\title{
Deterritorialization and Traumatic Experiences of the Protoganist in Oleander Girl
}

\author{
V. Samuel Morris, M. Poonkodi
}

\begin{abstract}
The paper aims to analyse the novel Oleander Girl and explore the plight of the protagonist Korobi, a young girl who goes to America in search of her identity which she believes to have lost in India due to her parent's cohabitation. Since her mother's live in relationship with an Afro-American could not be solemnized in India due to the intervention of her grandparents, she has to bear the brunt as a child born out of wedlock. The mystery of her birth is known to her only when she goes in search of her father to America. The main reason of her visit to America is to find out her identity as to whom she was born. During her endeavour to trace her father, she comes across situation which question her identity and her whereabouts which in turn bring forth inexplicable woes to her. The author, Chitra Banerjee attempts to expose that America though a land of freedom has not assured any safety to Korobi until she metamorphoses herself to be one like an American uprooting her true identity as an Indian. Now her transformations both physically and mentally instils confidence and she succeeds in locating her father. Korobi so long believed that knowing about her father would help her in quenching her thirst to establish her identity but in vain. Her father does not manifest any paternal instincts towards her. Though disappointing, Korobi learns to pursue her life as a transformed new woman bearing a new identity by re rooting in an alien land.
\end{abstract}

Key words: Diaspora, freedom, identity, homeland, women.

\section{INTRODUCTION}

'Diaspora' is a term which refers to the people, who leave their homelands, and settle in other parts of the world. It is either because they are forced to do or they willingly leave their homeland. In the history of human civilization, there are numerous events of diaspora. Jews were the first Diasporas in the history of mankind.

Indian migration to different parts of the world could be classified into three main phases; Firstly the emigration is to British, French and Dutch colonies. A new system of contract labour, the indenture system, was introduced to engage Indian workers for five to ten years contract on a meagre salary. Under this system a number of people migrated to, British, French, Dutch, Uganda, South Africa, West Indies etc., Most of these people were illiterate and belonged to lower strata of the society. They were mostly treated as slaves. They also suffered the problem of racial or ethnic discriminations. Secondly the emigration is to developed world countries of Europe, Canada and USA. These included highly qualified professionals like Doctors, Engineers, Charted accountants, Businessmen etc., they did not face such difficulties as faced by the earlier migrants during colonial times. Today because of their positive contribution to the development of the migrated country, some Indians have not only acquired political role for themselves but are also heading some political offices. Though number of such people has acquired the citizenships of their respective nations, yet they continue to hold linkages with Indians or Indian culture by one way or the other. Thirdly the emigration is to West Asia: Oil as an important factor in the economy of West Asian States. Hence large number of skilled and unskilled Indians migrated to Gulf countries. They headed for west Asia to reap a part of the bountiful harvest of local prosperity.

Indian diasporic people are nostalgic about their village, culture, language, food, cinema etc., these people construct imaginary homeland in the foreign land to fulfil the gaps of the homeland anxiety at a distance. Margaret Abraham in her article, "Model Minority and Martial Violence, "asserts that "ethnicity, gender, class, race, and citizenship are all important aspects of the construction of self and community for South Asian immigrants in the United States" (198).

According to Lisa lau, "American-Indian women who are "the most prolific of the contemporary South Asian women writers" (Lau 238). Chitra Banerjee is one of the Indianborn American writers. Her work has appeared over fifty periodicals including magazines such as Atlantic Monthly and Newyorker and been part of over fifty anthologies. Her books are translated into twenty nine languages and some of them are made into movies. She is an activist particularly in the fields of literacy and women rights. She focuses mainly on the psychological exploration of the inner mind of her characters in her writings. All her women characters in India are deeply rooted in the culture, traditions and religious belief systems practised in their patriarchal family structure.

The select novel, Oleander Girl, traces the life of the protagonist, Korobi Roy. She is brought up by her grandparents and is given the identity of Roy family. She is ignorant of her true identity. Later her grandmother unravels a mystery about her birth and her parentage. She sets forth to America in search of her identity and family secret.

\section{DISCUSSION\& RESULTS}

The novel deals with an eighteen years old orphan, Korobi. She is parented by her grandparents. Her grandfather, Bimal Roy, a retired barrister, is a conservative old man. On the contrary, her grandmother, Sarojini, is a warm-hearted person. In her childhood Korobi has yearned for her parents' love. The only fact that Korobi is let known about her parents is that her mother Anu died during parturition and her father died in a car crash three months before her mother's death.

Revised Manuscript Received on 14 August, 2019.

V. Samuel Morris, Karunya Institute of Technology and Sciences, Coimbatore, Tamil Nadu, India. (Email: samenglizlit@gmail.com)

M. Poonkodi, Karunya Institute of Technology and Sciences, Coimbatore, Tamil Nadu, India. 


\section{DETERRITORIALIZATION AND TRAUMATIC EXPERIENCES OF THE PROTOGANIST IN OLEANDER}

GIRL

Korobi desires to look into the facts about her parents but she could not. She is affianced to Rajat Bose who is from a rich Bengali family. The day of her engagement reveals many truths. Korobi sees her mother's shadow in a dream in the morning and is afraid to share it with her grandfather. She says, "From time to time, I imagined- a mix of horror and pride- what Grandfather's reaction would be when he saw me in it." (Oleander girl, 18). The sudden death of her grandfather unties Sarojini from her promise and reveals Korobi the truth about her parents that completely ruins her peaceful life. She clusters information about her parents from her grandmother that Anu, her mother, was in love with a foreigner, Rob Lancey, during her stay in America when she had been there for her higher studies. Because of her premarital relationship with him she gets pregnant. During her pregnancy she longs to be with her parents in India. She gets the permission from her father, flies to her hometown and spends the happiest times of her life with her parents. During her stay in India she tries to convince her father to allow her to marry Rob but the conversation results in an argument and he denies her permission to return back to America but unexpectedly she slips from the staircase and starts bleeding. She is taken to the hospital and is found dead when Korobi is operated and taken out. This discovery about her parents shatters Korobi's sense of self and takes her out of her sheltered Kolkata life motivates her into a search. She says to her fiancé Rajat, "I'm so confused. All the things I was so proud of, my family, my heritage- they're only half- true. The other half of me-I don't know anything about it. Except that all this time my father was alive, and in America" (Oleander Girl, 66)

Knowing the fact that her real identity lies across the ocean, the United States, Korobi decides to leave to America to find her father and her identity. Finding her father in an unknown country without having his photograph and knowing only his first name becomes very difficult for her. Korobi talks to Rajat about her desire and her decision to know about her own father. She determines to take a challenge to explore the whereabouts of her father in a foreign land. Though she is insisted to marry first, she never wants to get tangled in this relationship and puts aside her marriage plans. Divakaruni describes Korobi as a wilful, charismatic young Indian woman and is unafraid of people and their comments. She just wants to follow her heart and boldly declares, "But neither do I want to be a trouble to you. I understand how much of a problem for you my heritage has become"... "If it is so important for your business, I'm willing to release Rajat from the engagement." (Oleander Girl, 79) Rajat tries to persuade her explaining about the less possibilities in finding her father, but she still says, "I don't care!" (Oleander Girl, 71). Now Korobi is determined to fly to America, she asserts, "I'm even prepared to go to America." (Oleander Girl, 72). Knowing all the adversities and misfortunes on the way, like other immigrants Korobi decides to give up her peaceful, satisfying and secured life in Kolkata and is ready even to sacrifice her love in order to find her identity and chooses a challenging path and ventures to America. "Although such experiences are stressful, they also provide opportunities for creating a 'new' identity" (Ramaswami, et al. 151).
In the words of Sri Aurobindo "The great are strongest when they stand alone, A God - given might of being is theirforce"'.Being alone in America Korobi goes through hard times without knowing her real identity. Chitra Banerjee's concern and sympathy are primarily for the woman. The first hardship Korobi faces is at Kennedy airport where she waits for Mitra who is arranged by Rajat to pick Korobi from the airport but he doesn't show up. Starting with this she faces numerous hardships. Korobi is assisted by Desai, a detective agent, who is also appointed by Rajat to help in finding her father in America. There she meets Vic, Desai's nephew. He works as a part time assistant and is the only one who understands Korobi's feelings. He offers his support to Korobi to find her father. Mr. Desai shortlists three names: Rob Evanston, an architect, Rob Mariner, an estate lawyer in San Francisco and Rob Davis, a writer, in the Santacruz club. Korobi meets all the three men and to her disappointment finds that they are in no way related to her. In fact one of them tries to sexually harass her and one thinks that she is out there for money. These experiences shatters her and she is about to give up.Korobi's hope was revived after meeting Meera Anand and she accepts of knowing her mother Anu Roy. It is through this woman, Korobi comes to know that her father is an AfroAmerican and her parents were unmarried.

Bhattachariya asserts that "Immigrants do not simply accept the 'melting pot' roles expected of assimilated Americans" - instead they continually redefine their sense of identity". When Korobi plans to travel to California in search of her father, she realises that she is out of money. Mr. Desai suggests her to call her fiancé and ask him to wire her some more funds. But she is very stubborn and not ready to ask any amount from anyone especially from Rajat. She says, "I'll get the money, I say with jaunty rashness, though I have no idea how. I know this much, though: I'm not going to ask Rajat" (Oleander Girl, 172). Instead she decides to sell her hair and earns money for her living in America. This makes her feel even more confident and declares, "I feel light-headed, untethered. But once the money is in my hand I'm somewhat consoled. I now have enough for California; I have done it without having to beg anyone". (Oleander Girl, 177). Divakaruni describes this young Indian woman with immense courage.

When Korobi finds her biological father, he tells about his visit to India in search of Anu and his daughter but was informed by her grandparents that both of them were dead. He also explains that now he is married and has three children. Korobi is shaken by the truth and realises that she is an illegitimate child and this made her feel suffocated. During her stay in America she gets attracted to Vic who understands and supports in all her endeavours and is tempted to continue her life with Vic when he approaches her. Now Korobi has a choice to stay back in America as she loves the place. She says, "I'll have to make my new decision: Vic or Rajat, America or India" (Oleander Girl, 218). 
The values that she learnt from her grandparents in India, faithfulness for her fiancé and many other feelings about being Indian brings her back to India. She returns as a better person knowing what is right for her and to resist temptations. She unties herself from the web of identity crisis being the beautiful oleander that her mother wanted her to be. She achieves a sense of fulfilment.

Korobi's newly found facts opened up a different dimension to the existence of life. Korobi's courage and stubbornness enables her to keep going even when facing a setback. This can be the reason why Korobi didn't get disappointed when she is abandoned by Rajat. After coming back to India she is rejected by Rajat and his mother, as they could not accept the changes in Korobi's attire, haircut and her attitude. But she is bold enough to face the trail and returns his engagement ring with dignity.

\section{CONCLUSION}

As a diasporic writer, Chitra Banerjee, in most of her novels gives an opportunity to understand the immigrant's quest for identity and their struggle with identity crisis in a foreign land. She brings to limelight, the life of migrants standing in-between the two worlds, ambivalence towards dual belongingness between the homeland and the host. They risk their life to succeed in a new environment and struggle to enhance their families and also their own life. Mostly women migrants are tested between domestic life and professional life. The politics of multiculturalism and double consciousness ends in disadvantage and jeopardize the future of migrants. One of the major themes of the novel is identity crisis. In contrast to other diasporic characters, the protagonist in this novel takes her journey from India to America in search of her own identity. Korobi undergoes strict rules and an overprotective life in India where she has to protect the family bondage, culture, tradition and is not let to decide on her own but situations push her to find her real identity that takes her to America. The migrated land draws her to western cultures and moulds her to become strong enough through troublesome encounters and find her real identity by herself. The quest of identity leads Korobi to self-discovery.

\section{REFERENCES}

1. AhmBanerjee, Chitra Divakaruni. Oleander Girl. New Delhi: Penguin Books India, 2013.

2. Bhattacharya, Gauri. "The Indian Diaspora in Transnational Context: Social Relations and Cultural Identity of Immigrants to New York City." Journal of Intercultural Studies 29.1 (2008): 65-80.

3. Espín, Oliva. "Gender, Sexuality, Language, and Migration." Ed. Ramaswami Mahalingam. Cultural Psychology of Immigrants. Mahwah, N.J.: Lawrence Erlbaum, 2006. $150-258$.

4. Margaret, Abraham. "Model Minority and Marital Violence: South Asian Immigrants in the United States." Ed. Ramaswami Mahalingam. Cultural Psychology of Immigrants. Mahwah, N.J.: Lawrence Erlbaum, 2006. 197-216.

5. Lau, Lisa. "Making the Difference: The Differing Presentations and representations of South Asia in the Contemporary Fiction of Home and Diasporic South Asian Women Writers." Modern Asian Studies. 39 (2005): 237-257.
6. Sri Aurobindo's, 'Savitri', Published by Sri Aurobindo Ashram Publication Department, Pondicherry, India, 1997. 